\title{
An Evaluation of the Procedures required to ensure Consistent Material Supply in the Eastern Cape Automotive Industry
}

\author{
G S Horn and F Janse Van Rensburg \\ Department of Logistics Management, \\ Nelson Mandela Metropolitan University
}

\begin{abstract}
There is a common perception that logistics practice and supply chain management have not yet reached the required international standards among all the supply chain members in the South African automotive industry. This article is based on a research study that investigated possible reasons for the inconsistent supply of materials in the Eastern Cape automotive industry specifically. Problems identified include the fact that suppliers are not evaluated on a regular basis and do not receive sufficient logistics training, while a commitment and will to the development of local suppliers is lacking. Recommendations made to the South African automotive industry include the improvement of development programmes to assist local suppliers in becoming world-class suppliers, better logistics training, more regular supplier assessments, as well as improved mutual communication among suppliers and motor vehicle assemblers.
\end{abstract}

JEL M1, M2, M11

*The NRF is acknowledged for its financial assistance in this research project

\section{1}

\section{Introduction}

Organisations in today's highly competitive, global marketplace are under constant pressure to find new and improved ways to create and deliver maximum value to their customers. The twin goals to meet are cost reductions (in order to offer goods at more competitive prices) and higher levels of customer service (Coyle, Bardi \& Langley, 2003: 222). Customer service has in fact become a key differentiator as the sophistication and demands of customers continually change and/or increase. Prices, on the other hand, are under continuous pressure because of factors such as a fluctuating currency, higher fuel costs, global competition that may lead to over-capacity, as well as high logistics costs due to inefficiencies.

Against this background, there has been a growing recognition in the business world that effective and efficient logistics and supply chain management are two major interdependent instruments for organisations to apply in order to better manage the 'pipeline' in which they operate and thus reach the twin goals of cost reduction and customer service enhancement. In the automotive sector globally, both manufacturers and dealers are well aware that if they fail to focus their energies around competition based on customer satisfaction, their customers will desert them in favour of those who offer alternative and improved supply chain approaches (Reynolds \& Eisenfelder in Gattorna, 1999: 618). Unfortunately, there is a common perception that logistics and supply chain management have not yet reached the required international standards among all the supply chain members in the South African automotive industry. This causes various disruptions in the different automotive supply chains, such as late deliveries from suppliers, short-shipments, incorrect deliveries and deliveries at incorrect delivery points. 
This article extends the ideas of Janse van Rensburg (2004) who investigated possible reasons for the inconsistent supply of materials in the Eastern Cape automotive industry specifically. The objective of the article is to outline some of the causes of these disruptions in supply chains in the automotive industry, and to make recommendations on how to improve the flow of materials and component parts in a supply chain. The implementation of these recommendations should ensure a more consistent supply of materials and finished products in the South African automotive industry.

\section{3}

\section{Fundamental Front-end Processes}

Successful supply chain management requires many decisions that relate to the flow of information, products and funds (Chopra \& Meindl, 2004: 7). Several front-end processes are therefore regarded as being fundamental and require thorough planning before any type of activity can begin in a supply chain similar to that found in the automotive industry. These include: a specific supply chain strategy, a (possible) restructuring of existing logistics networks, product design and specification, production processes and sequences that need to be engineered and tested, as well as the planning of inventory management, among others (Ballou, 1999: 9).

However, since the research focused on a supply chain/logistics viewpoint, the following three front-end processes were selected for investigation:

- the supplier selection process,

- the use of information technology,

- the transportation function.

\section{4}

\section{Research methodology}

Janse van Rensburg's literature study determined the theoretical guidelines for logistics and supply chain management in a modern business environment. It focused on the timely supply of materials and finished products to the point of customer receipt. An empirical study was then conducted to establish the physical manner in which theory is applied and executed in the automotive workplace. The use of a questionnaire, supported by personal interviews, was chosen as the best way of collecting the required information. Based on the above-mentioned three front-end processes, the questionnaire was divided into the following three sections:

- Section A: The supplier selection process, continuous relationships, supplier evaluation and development.

- Section B: The importance of information technology for the planning and control of logistics.

- Section C: The importance of the transportation function in logistics and the impact it has on the automotive industry.

The questionnaire was completed by carefully selected contact persons at each of the four motor vehicle assemblers and at thirty-four of the bigger motor component suppliers in the Eastern Cape Province who were identified by the four motor vehicle assemblers. The contact persons were recommended by the management of the respective organisations where they are employed, based on their experience and expert knowledge in the fields of logistics and supply chain management. The motor vehicle assemblers are General Motors, DaimlerChrysler, Volkswagen and Ford. The suppliers involved varied in terms of business turnover, number of employees, organisational structure and types of products.

Before commencing the survey, the questionnaire was evaluated for non-ambiguity, relevancy, transparency, general validity and interpretation. The final format of the questionnaire was decided upon after the research team was satisfied that it had been properly adapted for the specific objectives of the study. Because of the nature of the questionnaire, the Windows-based SPSS (Statistical Package for the Social Sciences) software package was used. This software package is a complete package that is used to 
enter, analyse, graphically display and report information. This computer package also allows the user to capture open-ended questions as they appear on the questionnaire.

In order to minimise the measurement errors associated with a one-shot survey of this nature and to verify the authenticity of the gathered information, it was decided to run as many crosstabulations as possible. The data obtained in this study can therefore be considered reliable, as every precaution was taken to ensure that questions were clearly understood before the responses were recorded. The questionnaire elicited information from the respondents on 58 items that are related to the possible causes of disruptions in supply chains in the automotive industry. The responses obtained have been translated into tables, and these tables were analysed and interpreted. The results enabled Janse van Rensburg to determine the degree to which the local automotive industry has advanced towards accepted international logistics practice, as well as the extent to which supply chain management, as a total integrated concept, has been established within the automotive industry business setup.

\section{5}

\section{Practice versus theory in the Eastern Cape automotive industry}

In this section the empirical results obtained from the completed questionnaires are discussed and compared with the theoretical guidelines. Because of space limitations, only six of the fifty-eight tables used in the study are included in the text of this article. The discussion in the article, however, relates to all the information obtained.

\subsection{The supplier selection process}

Hugo, Badenhorst-Weiss and Van Rooyen (2002: 152), as well as Van Weele (2005: 32), state that the selection of the right supplier(s) is a critical decision in the purchasing process, and that an approved supplier list has to be kept and reviewed regularly. This process ensures that approved suppliers are available to supply the necessary components of the required quality without any delay. A good test of whether a firm has selected the right supplier(s) and the right number of suppliers is to analyse what impact the deleting or adding of a supplier will have (Chopra et al., 2004: 394).

\section{Table 1}

Organisations with a supplier selection procedure in place

\begin{tabular}{|l|c|c|c|c|}
\hline Organisations & Qty Yes & \% Yes & Qty No & \% No \\
\hline MVAs & 4 & 100.00 & 0 & 0.00 \\
\hline Suppliers & 32 & 94.12 & 2 & 5.88 \\
\hline
\end{tabular}

${ }^{*}$ MVAs $=$ Motor Vehicle Assemblers.

It is shown in table 1 that all four of the Eastern Cape motor vehicle assemblers and 94.1 per cent of the suppliers interviewed in the study have a specific supplier selection procedure in place. A list of approved suppliers with whom orders are placed, is kept and updated regularly by all the responding motor vehicle assemblers and suppliers.

\section{Table 2}

Organisations with a supplier performance evaluation and rating system in place

\begin{tabular}{|l|c|c|c|c|}
\hline Organisations & Qty Yes & \% Yes & Qty No & \% No \\
\hline MVAs & 4 & 100.00 & 0 & 0.00 \\
\hline Suppliers & 27 & 79.41 & 7 & 20.59 \\
\hline
\end{tabular}

According to table 2, all four motor vehicle assembler respondents have a supplier performance evaluation and rating system in place to evaluate their suppliers in terms of quantity accuracy and conformity to quality specifications, while 79.4 per cent of the suppliers have such a system in place to evaluate their own suppliers. 
Table 3

Number of times organisations evaluate their suppliers

\begin{tabular}{|l|c|r|c|c|}
\hline Period & $\begin{array}{c}\text { Qty } \\
\text { MVAs }\end{array}$ & $\begin{array}{c}\text { \% } \\
\text { MVAs }\end{array}$ & $\begin{array}{c}\text { Qty } \\
\text { Suppliers }\end{array}$ & $\begin{array}{c}\% \\
\text { Suppliers }\end{array}$ \\
\hline Monthly & 3 & 75.00 & 10 & 29.41 \\
\hline Quarterly & 0 & 0.00 & 8 & 23.53 \\
\hline Biannually & 0 & 0.00 & 1 & 2.94 \\
\hline Annually & 1 & 25.00 & 8 & 23.53 \\
\hline Very seldom & 0 & 0.00 & 7 & 20.59 \\
\hline Total & 4 & 100.00 & 34 & 100.00 \\
\hline
\end{tabular}

Table 3 indicates that three of the four responding motor vehicle assemblers and 29.4 per cent of the suppliers evaluate their suppliers on a monthly basis. One motor vehicle assembler and 23.5 per cent of the responding suppliers evaluate their suppliers annually only, while 20.6 per cent of the suppliers indicated that they seldom evaluate their suppliers. This is not sufficient, as suppliers have to be evaluated and measured more regularly to ensure that they live up to expectations and perform in terms of both quality and their contract (Hugo et al., 2002: 152).

Of concern is the view of the respondents that they experience more disadvantages than advantages when trying to develop local sources of supply. Despite the South African government constantly urging bigger, established organisations to become involved in the development of local small, medium and especially previously disadvantaged suppliers, the inclination among the respondents is to source from foreign world-class suppliers. Several well-known authors on supplier selection, evaluation and development emphasise the importance of and the benefits that accrue to organisations that are involved in the development of their existing as well as potential new suppliers (Burt, Dobler \& Starling, 2003: 156; Stock \& Lambert, 2001: 493). They argue that such assistance in creating good, better and exceptional suppliers allows organisations to reap rewards such as access to the latest technology, improved prices, a reduction in inventories and shorter delivery lead times - all factors that place a business in a better position to meet its competitive challenges. The respondent organisations in the Eastern Cape, however, indicated that they experience the opposite and therefore lack the will and commitment to become involved in developing local suppliers.

Three of the four responding Eastern Cape motor vehicle assemblers and 50.0 per cent of the supplier base indicated that they had provided training to their suppliers during the two years preceding the study, although the training sessions did not include any form of logistics training. The four motor vehicle assemblers only provide logistics training when new systems are introduced or when regular problems are experienced with a certain supplier. Only 2.9 per cent of the suppliers offering training to their suppliers included logistics training.

Since the late 1990s, the global trend is for buying organisations to develop closer relationships and/or partnerships with their suppliers (Leenders, Johnson, Flynn \& Fearon, 2005: 502). A reason for this is that suppliers are often closer to customers and are also continually exposed to innovations from other organisations. New ideas and innovations from suppliers are especially important during the early development of new products. Suppliers are then able to criticise future designs, suggest the use of alternative materials, and come up with ideas for more efficient manufacturing at a stage when engineering changes can be made without severe cost consequences (Van Weele, 2005: 187). Other advantages of working together include the continuous improvement of products and processes, reduced lead-times, faster delivery, as well as the achievement of higher quality (Leenders et al., 2005: 502).

As manufacturing businesses outsource more functions in order to focus on their core competencies, they increasingly expect their suppliers to deliver innovative and quality products on time and at competitive prices (Burt et al., 2003: 513). Closer relationships and co-operation between buyers and sellers, however, are not only limited to production processes, but to all the respective logistics functions in a supply chain. In the case of transportation, for example, if a buyer has 
relatively little expertise in the traffic area, while the supplier has a skilled logistics department, it might be wise to rely on the supplier's judgement in carrier selection and routing (Leenders et al., 2005: 186).

A formal suggestion scheme, whereby suppliers have the freedom and are encouraged to make recommendations, is thus strongly recommended. However, a prerequisite for the success of such a partnership and suggestion scheme is that the suppliers should have a genuine interest in continuous improvement and should be committed to do much more than merely fulfilling their contracts (Van Weele, 2005: 191). Unfortunately, it was found in the study that only one of the four motor vehicle assembler respondents has a formal suggestion scheme in place. Furthermore, only 26.5 per cent of the supplier respondents indicated that they have a formal suggestion scheme in place and a maximum of only two suggestions had been introduced and accepted during the year preceding this study.

Although supplier selection may have been conducted with great care, suppliers' performance can deteriorate over time for various reasons. Burt et al. (2003: 496) state that two common approaches are used to motivate suppliers to perform satisfactorily: reward and punishment. The biggest reward for satisfactory performance is follow-on business. The greatest punishment for unsatisfactory performance is not to award contracts for future requirements. Other means of punishment include the downgrading of a supplier, thereby reducing future business opportunities, as well as the bill-back method. Under bill-back, incremental costs resulting from poor quality and late deliveries are identified and then billed back to the appropriate suppliers, while overdeliveries of materials could be returned to the appropriate suppliers for their own account.

All four motor vehicle assemblers have a supplier reward/punishment system in place, while only 26.5 per cent of their supplier base has one in place. However, only 34.2 per cent of the responding organisations indicated that they make use of these punishments, and only in extreme situations. The four motor vehicle assemblers use various reward methods to motivate their suppliers for good performance, for example, by hosting an annual awards function. One motor vehicle assembler also makes use of a recognition letter and in-house magazine, while another makes use of a notice board to give recognition for good service.

It is interesting to note that the majority of suppliers are not allowed to rate the motor vehicle assemblers they supply, while only 23.5 per cent of the suppliers allow their suppliers to rate them. One of the four motor vehicle assemblers plans to introduce such a rating system in 2005. The perception seems to exist in most organisations that if you are the customer you do not need to be rated. Chopra et al. (2004: 389), however, suggest that organisations conduct regular surveys during which suppliers are asked to describe in detail how they experience their interaction with the procuring organisations. Burt et al. (2003: 496) point out the fact that one needs to be willing to improve one's own business interactions before asking one's suppliers to improve theirs.

\subsection{The use of information technology}

Information sharing is a key enabler of effective supply chain management, and information technology is increasingly being used as a "vehicle of use" (Burt et al., 2003: 335). The result is that logistics systems are becoming electronic as manufacturers, suppliers, distributors, retailers and customers are electronically linked through the Internet and other forms of digital communication (Voortman, 2004: 112).

\section{Table 4}

Organistions making use of different communication methods

\begin{tabular}{|l|c|c|c|c|}
\hline Methods & $\begin{array}{c}\text { Qty } \\
\text { MVAs }\end{array}$ & $\begin{array}{c}\text { \% } \\
\text { MVAs }\end{array}$ & $\begin{array}{c}\text { Qty } \\
\text { Suppliers }\end{array}$ & $\begin{array}{c}\% \\
\text { Suppliers }\end{array}$ \\
\hline E-mail & 4 & 100.00 & 34 & 100.00 \\
\hline Fax & 4 & 100.00 & 32 & 94.12 \\
\hline Internet & 4 & 100.00 & 26 & 76.47 \\
\hline EDI & 4 & 100.00 & 14 & 41.18 \\
\hline E-commerce & 0 & 0.00 & 3 & 8.82 \\
\hline
\end{tabular}


Table 4 shows that some 41.2 per cent of the suppliers who responded in the study make use of electronic data interchange (EDI), while 76.5 per cent use the Internet as their main means of communication. However, most of the responding suppliers indicated that they do not experience the advantages of EDI and the Internet as promoted by the motor vehicle assemblers and in the literature, but are forced by the assemblers to use them. The main reason why they do not experience the full benefits of EDI is because they do not cascade EDI down into their supplier bases.

Although it is argued in the literature that ecommerce will become the key to survival in the modern information era (April \& Cradock, 2000: 1), none of the motor vehicle assembler respondents use e-commerce or e-procure to order materials electronically, while only three (8.8 per cent) of the thirty-four responding suppliers make use of e-commerce. The main reason for this is that they believe that the initial cost outlay is too high and therefore perceive eprocurement to be non-beneficial at this stage. These results confirm the argument of Vogt, Pienaar and De Wit (2002: 264) that the eprocurement of materials for the manufacturing process is still in its development phase.

Table 5 shows that three of the motor vehicle assemblers use SAP as their main software package, while the fourth uses BAAN. In contrast, only three of the thirty-four suppliers (8.82 per cent) make use of either SAP or BAAN, while twenty-five (73.5 per cent) make use of various other systems, mainly accountancy programmes. These suppliers indicated, however, that these systems do not assist them in planning their logistics activities at all. The other concern is that 17.7 per cent of the suppliers do not have a main software package. According to Schönsleben (2000: 318320 ), most logistics packages have not yet achieved the level of integration attained by the SAP R/3 package. This package is suitable for both medium-size and larger organisations. It can also be linked to a third party's non-SAP software (SAP Southern Africa, 2003; Will, Hienger, Strabenberg \& Himmer, 1999: 22). This was confirmed by the four responding motor vehicle assemblers in the study who were linked to a third party.

Table 5

Software packages used by organisations

\begin{tabular}{|l|c|c|c|c|}
\hline $\begin{array}{l}\text { Main } \\
\text { software } \\
\text { package }\end{array}$ & $\begin{array}{c}\text { Qty } \\
\text { MV's }\end{array}$ & $\begin{array}{c}\text { \% } \\
\text { MVAs }\end{array}$ & $\begin{array}{c}\text { Qty } \\
\text { Suppliers }\end{array}$ & $\begin{array}{c}\% \\
\text { Suppliers }\end{array}$ \\
\hline SAP R3 & 3 & 75.00 & 1 & 2.94 \\
\hline BAAN & 1 & 25.00 & 2 & 5.88 \\
\hline Other & 0 & 0.00 & 25 & 73.53 \\
\hline None & 0 & 0.00 & 6 & 17.65 \\
\hline Total & 4 & 100.00 & 34 & 100.00 \\
\hline
\end{tabular}

Schönsleben (2000: 314) is of the opinion that the lifespan of most software packages is ten to twenty years. The average lifespan of the four motor vehicle assemblers' main software packages was given as 13 years, and that of the suppliers as 8.5 years. Firms should upgrade and maintain their software packages regularly during their lifespan - through system additions, deletions and enhancements - to ensure that they continuously meet the growing and changing environmental requirements.

All four responding motor vehicle assemblers make use of secondary logistics packages to support their main software packages, while only 14.3 per cent of the suppliers make use of these. Two of the four motor vehicle assemblers use the Collaborative Xchange (CX)-system and Clockworks, or are planning to use them. $\mathrm{CX}$ and Clockworks provide the motor vehicle assemblers with improved shop floor control in real time, and are therefore used as an inplant support system. They are officially recognised by the National Association of Automobile Manufacturers of South Africa (NAAMSA) and the National Association of Automotive Component \& Allied Manufacturers (NAACAM), South Africa's automotive controlling bodies, as being the leading EDI software solutions for the automotive industry in lean supply environments (Clockworks, 2003).

Three of the four responding motor vehicle assemblers also make use of internal logistics packages. Schönsleben (2000: 331; 336; 342) 
argues that if a certain package does not meet the objectives that a firm has set itself, the set goals will not necessarily be achieved by using a different package. It is therefore suggested that the automotive organisations in the Eastern Cape use secondary support logistics packages, because none of the main software packages provides them with all the necessary functions.

There are various security techniques available to secure an organisation's communication system. In 1998, the Computer Security Institute/Federal Bureau of Investigation (CSI/FBI) determined that 81.0 per cent of American organisations use firewalls (Greenstein \& Feinman, 2000: 267-268). Organisations should, however, use firewalls in conjunction with other security techniques as they are not foolproof. The concern is, therefore, that only 62.5 per cent of the Eastern Cape motor vehicle organisations use firewalls and even fewer of the other security techniques available to them. The integrity and security of their systems are therefore clearly compromised.

It was found that all four of the motor vehicle assemblers and 89.3 per cent of the suppliers in this study have communication system representatives. However, some of them failed to meet regularly to solve problems, consider changes and/or improve the accuracy and reliability of their systems. Regular meetings and collaboration are of extreme importance in achieving world-class standards in information technology, as well as for planning and controlling logistics (Hugo et al., 2002: 281).

\subsection{The transportation system}

The transportation system is the physical link connecting an organisation's customers, raw material suppliers, plants, warehouses and channel members - the fixed points in a logistics supply chain (Coyle et al., 2003: 338). Transportation has a large impact on both responsiveness and efficiency, while the type of transportation used affects the inventory levels and facility location in the supply chain (Chopra et al., 2004: 59).
The South African government is fully aware of the challenges that need to be addressed to achieve the desired shift from road to rail transport (Freight \& Trading Weekly, 19 July 2002: 14; 4 October 2002: 3). According to Bailey (2001: 4), it will not be possible to force the automotive industry in the Eastern Cape to use rail transport if it is not economically viable and the service better than the current road transport system. Three of the four responding motor vehicle assemblers and 91.2 per cent of the suppliers do not think that the South African government will accomplish the proposed shift from road to rail transport. Those who believe that the government might accomplish its objectives, set the following pre-conditions for success:

- improved prices and competitiveness

- improved infrastructure

- the introduction of an incentives scheme

- privatisation and owner control.

\section{Table 6}

Organisations that have a carrier selection process in place

\begin{tabular}{|l|c|c|c|r|}
\hline Organistions & Qty Yes & \% Yes & Qty No & \% No \\
\hline MVAs & 4 & 100.00 & 0 & 0.00 \\
\hline Suppliers & 15 & 44.12 & 19 & 55.88 \\
\hline
\end{tabular}

It is shown in table 6 that all four motor vehicle assemblers in the study have a carrier selection procedure in place, while only 44.1 per cent of the suppliers have such procedures in place. Only two of the four motor vehicle assemblers use their own transport: on average they use four trucks for short distances within their plants, between plants and from the harbour to their premises. Altogether 82.4 per cent of the responding suppliers make use of their own transport as well as other transport service providers. Some 25.0 per cent rely exclusively on their own transport to make deliveries to their customers.

Not one of the four responding motor vehicle assemblers makes use of brokers, while all four make use of professional (contract) carriers, freight forwarders and third party logistics providers. The third party logistics provider 
option has become an increasingly popular alternative, as confirmed by the results of the study as well as the literature (Coyle et al., 2003: 417; Vogt et al., 2002: 38). All four Eastern Cape motor vehicle assemblers evaluate their carrier's performance, while only 66.7 per cent of the suppliers who use a carrier do this at regular intervals. According to Coyle et al. (2003: 378), a regular evaluation process is required to ensure that the carrier that was awarded the business remains competitive.

All the responding motor vehicle assemblers' transport carriers have surveillance equipment in place, while only 51.9 per cent of the transport carriers used by suppliers have surveillance equipment in place. Three of the four motor vehicle assemblers' transport carriers use an online tracking system, namely EDI, to trace material in real time.

Two of the four motor vehicle assemblers require that their transport carriers issue them with an incident report for damaged or lost material, while 77.8 per cent of the suppliers require that their transport carriers issue them with an incident report for damaged or lost material. It was also found that not many of the transport carriers have an annual awards function during which they award their accident-free drivers with certificates or announce the driver of the year. None of the four motor vehicle assemblers sponsor the award functions of transport carriers, while only 7.4 per cent of the suppliers who use other transport service providers, sponsor them. Coyle et al. (2003: 378) argue that the value and significance of the continuous evaluation and development of transport carriers for the automotive industry cannot be overemphasised.

\section{6}

\section{Recommendations}

It is clear from the above discussion that both similarities and differences were found when the empirical results obtained from organisations in the Eastern Cape automotive industry were compared with the theory. These differences explain why interruptions are experienced in the material flow from suppliers to motor vehicle assemblers. For example, it was established that while the top management of the Eastern Cape motor vehicle assemblers realise the importance of logistics to their company, they have clearly not employed it to its full potential. On the other hand, suppliers in the Eastern Cape are generally not fully aware of the nature and importance of the total logistics model or part of it due to their lack of development and training.

It was also found that the motor vehicle assemblers pay more attention to their own computerised technology, except for the security aspect. Although they are in the process of improving communication with their suppliers, not much is being done to assist their suppliers in expanding the latter's computerised systems.

Based on the empirical results of the study, and because the automotive industry in the Eastern Cape contributes significantly to the South African automotive industry, the following recommendations are made to the South African automotive sector:

\subsection{Recommendations regarding the selection process}

- It is recommended that organisations in the South African automotive industry introduce more detailed purchasing procedures. Every supplier, for example, needs to be well informed of aspects such as clearly stipulated delivery schedules, acceptable lead times and minimum inventory levels. Furthermore, contracts are to be amended and brought up to date as and when delivery methods change. This will prevent any difficulties and misunderstandings between an organisation and its suppliers.

- A second recommendation is that organisations in the automotive industry visit their suppliers regularly and also invite suppliers to view first-hand how and where their material is used. There is a need to increase interaction and improve the relationship with suppliers by hosting supplier conferences, forums and feedback sessions. This can be achieved by establishing supplier associations and supplier clubs. 
- Organisations also need to design improvement programmes and/or action plans to develop existing suppliers into world-class suppliers, and to assist in the development of previously disadvantaged suppliers.

- In line with the previous recommendation, it is further recommended that organisations provide more training to their suppliers, especially in the logistics field. This training should not be restricted to the introduction of new systems or to address problems experienced with suppliers. Supplier improvement teams can be established in order to exchange ideas to improve the whole supply chain. Supplier training centres (STCs) can also be established in conjunction with tertiary institutions to provide assistance and practical training in logistics, supply chain management, delivery systems, packaging and lean supply. This will contribute to a more flexible and responsive supply chain.

- Organisations need to conduct supplier clinics on a regular basis to address concerns and problems. They should introduce formal suggestion schemes among their suppliers and deploy the new logistics ideas and innovations received from them. This will help to improve the logistics and quality of incoming materials and reduce lead times.

- It is also recommended that organisations that do not have a supplier reward system in place, introduce one as soon as possible, especially those suppliers who supply highvalue, critical production materials. More than one reward method should be used, which could include hosting an annual awards function, a recognition letter to the supplier, public recognition in a newspaper or in-house magazine, and/or the prominent display of the results on a notice board in the reception area of the organisation. Organisations should only use the punishment and penalty method in extreme situations where bad service has become common practice.
- It is further recommended that organisations in the Eastern Cape automotive industry allow suppliers to assess them regularly. This will allow an organisation to gain valuable feedback and input from its suppliers to improve its own logistics service.

\subsection{Recommendations regarding information technology}

- It is recommended that organisations in the automotive industry make more and better use of EDI and the Internet as communication media. This will improve the speed and quality of information flows through the entire supply chain, and therefore assist in reducing costs and reaction times.

- Motor vehicle assemblers need to commence with the planning and development of an effective integrated ecommerce system for the automotive industry. This will enable them to communicate and do business within a broader commercial environment, thereby reducing the cost of the total supply chain. E-procurement has to be part of this development.

- It is further recommended that suppliers in the automotive industry procure logistics software packages to assist them with their material resource planning (MRP) process. The motor vehicle assemblers can assist in ensuring that all their suppliers procure a standard logistics software package that will allow effective and efficient integration with their present software packages. It is suggested that organisations upgrade systems on a more regular basis, preferably once a year. Suppliers who do not have software packages should be requested to procure one within a certain period, or face removal from the approved supplier list.

- Organisations in the automotive industry should also introduce the use of more security techniques. It is essential to use passwords and firewalls in conjunction with encryption, hashing, and digital 
signature or challenge response to secure systems.

- A further recommendation is that communication system representatives of organisations meet more regularly to solve system problems, consider changes and improve the accuracy and reliability of systems in use. This will ensure that all systems meet the requirements of the users.

\subsection{Recommendations regarding the transportation function}

- It is recommended that motor vehicle assemblers as well as suppliers work together with the South African government to improve the service levels of rail transport in the country and make it economically more viable than road transport.

- Motor vehicle assemblers that make use of their own transport should consider outsourcing the transport function to a third party logistics provider. This will allow them to concentrate and spend more time on their core functions.

- It is further recommended that where possible, motor vehicle assemblers and their suppliers use the same third party logistics providers. This step will contribute towards better prices and improved service levels, as well as better business control over the third party logistics providers.

- A further recommendation is that organisations evaluate their carrier's performance more often, preferably monthly. This will motivate transport carriers to strive for continuous improvement.

- It is additionally recommended that transport carriers themselves evaluate organisations, to whom they provide service, regularly in terms of business performance. This will provide valuable feedback and input from them in areas where the organisation requires improvement, for example in devising packaging designs to alleviate possible packaging problems. Furthermore, organisations should request their transport carriers to issue them with incident reports in the case of damage or loss of material. This should help to reduce incidents of loss and damage.

- Organisations should make it a requirement for their transport carriers to host an annual awards function during which all accident-free drivers are presented with certificates and the 'Driver of the Year' announced. Organisations should sponsor these functions themselves. This practice will motivate drivers to be more safety conscious.

- Lastly, it is recommended that organisations make EDI a pre-requisite for transport carriers. The transport carriers should subsequently also have to plan the use of ecommerce. This will ensure more efficient and effective tracking and movement of goods at all times.

\section{7}

\section{Conclusions}

Based on the results of an empirical study and a comparison with relevant literature, the procedures required for consistent material supply were evaluated and various recommendations made for organisations in the automotive industry of both the Eastern Cape and South Africa. The implementation of these recommendations should ensure a more consistent supply of materials and component parts in the country's automotive industry.

\section{References}

1 ANON. (2002) Freight \& Trading Weekly, 19 July: $6,14,15$.

2 ANON. (2002) Freight \& Trading Weekly, 4 October: 3 .

3 APRIL, K.A. \& CRADOCK, J. (2000) EBusiness: Redefining the Corporate Landscape in South Africa, Butterworth: Cape Town.

4 BAILEY, M. (2001) Supply Chain Management, Centre for Logistics Excellence: South Africa.

5 BALlOU, R.H. (1999) Business logistics management, Prentice-Hall: London.

6 BURT, D.N.; DOBLER, D.W. \& STARLING, S.L. (2003) World Class Supply Management: 
The Key to Supply Chain Management, Higher Education McGraw-Hill: New York.

7 CHOPRA, S. \& MEINDL, P. (2004) Supply Chain Management: Strategy, Planning and Operations, Pearson Educational International: New Jersey.

8 CLOCKWORKS. http://clockworks.clex.co.za; downloaded 2003-06-29.

9 COYLE, J.J.; BARDI, E.J. \& LANGLEY, C.J. (2003) The management of Business Logistics, West Publishing Company: New York.

10 GATTORNA, J. (1999) Strategic Supply Chain Alignment: Best Practice in Supply Chain Management, Gower: Hampshire.

11 GREENSTEIN, M. \& FEINMAN, T.M. (2000) Electronic Commerce: Security, Risk Management and Control, McGraw-Hill: New York.

12 HUGO, W.M.J.; BADENHORST-WEISS, J.A. \& VAN ROOYEN, D.C. (2002) Purchasing and Supply Management, Van Schaik: Pretoria.

13 JANSE VAN RENSBURG, F. (2004) "An evaluation of the procedures required to ensure consistent material supply in the Eastern Cape automotive industry”, Port Elizabeth Technikon M Tech dissertation, Port Elizabeth.

14 LEENDERS, M.R.; JOHNSON, P.F.; FLYNN, A.E. \& FEARON, H.E. (2005) Purchasing and
Supply Management, McGraw-Hill Irwin: New York.

15 REYNOLDS, N. \& EISENFELDER, S. (1999) "Reconfiguring the automotive industry supply chain”. In Gattorna, J. Strategic Supply Chain Alignment: Best Practice in Supply Chain Management. Gower: Hampshire.

16 SAP SOUTHERN AFRICA. http://www.sap. com. downloaded 2003-06-25.

17 SCHöNSLEBEN, P. (2000) Integral logistics Management: Planning and Control of Comprehensive Business Processes, St. Lucie Press: New York.

18 STOCK, J.R. \& LAMBERT, D.M. (2001) Strategic Logistics Management, McGraw-Hill Higher Education: New York.

19 VAN WEELE, A.J. (2005) Purchasing and Supply Chain Management: Analysis, Planning and Practice, Chapman \& Hall: London.

20 VOGT, J.J.; PIENAAR, W.J. \& DE WIT, P.W.C. (2002) Business Logistics Management: Theory and Practice, Oxford University Press: Cape Town.

21 VOORTMAN, C. (2004) Global Logistics Management, Juta: Cape Town.

22 WILL, L.; HIENGER, C.; STRABENBURG, F. \& HIMMER, R. (1999) SAP R/3 Administration, Longman: New York. 